\title{
Optimization of the step feeding ratio for nitrogen removal by SBR using technique for order preference by similarity to ideal solution (TOPSIS)
}

\author{
Ngun Za Luai Mang, Yuhoon Hwang, Tae-Jin Lee ${ }^{\dagger}$ \\ Department of Environmental Engineering, Seoul National University of Science and Technology, Seoul 01811, Republic of Korea
}

\begin{abstract}
The performance of nitrogen $(\mathrm{N})$ removal was investigated by altering the influent step feeding in a sequencing batch reactor (SBR). The optimum condition for influent step feeding was analyzed using Technique for Order Preference by Similarity to Ideal Solution (TOPSIS) with entropy weight method, considering the $\mathrm{C} / \mathrm{N}$ ratio range 1.5 to 4.5 . The results showed that the SBR with the multi-step-feeding system achieved a high nitrogen removal rate of $92.7 \%$ at the three-step influent feeding mode. Nitrogen removal was significantly improved due to the multi-step influent feeding, which provided the required carbon source in the anoxic phase for the removal of nitrate that enhanced the denitrification process. The highest nitrogen removal rate at real-time operation was observed at the three-step feeding mode with $60 \%$ primary feeding, $30 \%$ secondary feeding, and 10\% tertiary feeding, respectively. TOPSIS analysis results also showed that the optimum step feeding ratio was identical to the real-time operation of the SBR.
\end{abstract}

Keywords: Influent step feeding, Nitrogen removal, SBR, TOPSIS

\section{Introduction}

The removal of nitrogen and phosphorous is one of the principal problems of wastewater treatment because of its negative impact on the aquatic environment. Despite the fact that nitrogen and phosphorous are nutrients that are natural parts of the aquatic ecosystem, their excessive concentrations lead to serious eutrophication of water bodies and threatening human health [1-3]. Therefore, the implementation of cost-effective technologies at wastewater treatment plants has gained global attention as the increase in stringent discharge regulations on nitrogen and phosphorous removal $[4,5]$. Conventional biological nitrogen removal (BNR) comprises two successive steps: autotrophic nitrification in aerobic conditions, and heterotrophic denitrification in anoxic conditions [6]. Many studies have been conducted and various approaches have been utilized in biological nutrient removal, such as the conventional suspended-growth activated sludge process, oxidation ditch process and anaerobic/anoxic/oxic (A/A/O) processes [7], moving bed biofilm reactor [8], and sequencing batch reactor $[9,10]$.

In general, the operating cycle of the sequencing batch reactor consists of fill, react, settle, and draw with a dedicated length, irrespective of fluctuations in wastewater strength and microbial activity [11]. In particular, the major contribution of SBR to total nitrogen (TN) removal is achieved by utilizing the organic substrates supplied from the influent at the beginning of each operation cycle, to reduce the remaining nitrate from the last cycle [12]. The removal of nitrogen in the SBR system can be achieved by alternating aerobic and anoxic periods during the reaction [13], allowing the nitrogen cycle to be completed. Biological nitrogen removal involves two processes: the oxidation of ammonia $\left(\mathrm{NH}_{3}\right)$ to nitrite $\left(\mathrm{NO}_{2}^{-}-\mathrm{N}\right)$, then nitrite to nitrate $\left(\mathrm{NO}_{3}{ }^{-} \mathrm{N}\right)$ through nitrification, and the reduction of nitrate $\left(\mathrm{NO}_{3}^{-}-\right.$ $\mathrm{N})$ to nitrogen gas $\left(\mathrm{N}_{2}\right)$ through denitrification [14]. In conventional SBR, denitrification is often limited because of the lack of sufficient carbon sources to sustain a high denitrification rate $[15,16]$. As a consequence, a high concentration of $\mathrm{NO}_{3}-\mathrm{N}$ or $\mathrm{NO}_{2}-\mathrm{N}$ is often remained in the effluent, giving low nitrogen
This is an Open Access article distributed under the terms of the Creative Commons Attribution Non-Commercial License (http://creativecommons.org/licenses/by-nc/3.0/) which permits unrestricted non-commercial use, distribution, and reproduction in any medium, provided the original work is properly cited.

Copyright (C) 2022 Korean Society of Environmental Engineers
Received December 11, 2020 Accepted April 17, 2021

${ }^{\dagger}$ Corresponding author

E-mail: leetj@seoultech.ac.kr

Tel: +82-2-970-6614 Fax: +82-2-971-5776

ORCID: 0000-0001-9532-5358 
removal efficiency. Furthermore, one of the most important control parameters for biological nitrogen removal is the concentration of dissolved oxygen (DO). Complete nitrification and organic carbon removal can be achieved by providing high DO concentration [17]. On the other hand, denitrification potential was declined with a high level of DO concentration in the water [18-20].

In order to secure these deficiencies of the conventional SBR, Lee et al. [21] developed the internal circulation sequencing batch reactor with step-feed to maximize the nutrient removal rate by controlling the concentration of $\mathrm{DO}$ by the circulation of supernatant in the reactor through the condensed sludge layer during the anoxic fill and anoxic step. The internal circulation of the supernatant makes lower hydraulic shear force; hence, lower DO level was observed, compared to the conventional SBR. On the other hand, higher denitrification efficiency was obtained by using this SBR system. Moreover, SBR has the ability to supply the required carbon source for denitrification by providing multiple-stage influent feeding. It has been well documented that the step-feed SBR has several advantages over the conventional SBR, as it can enhance the denitrification rate, further the total nitrogen removal rate [22], and is technologically and economically effective in enhancing nitrogen removal in activated sludge systems [23-26]. As the SBR process is time-oriented, the operation condition provides an additional degree of freedom to achieve the control target. A crucial issue affecting the performance of the step-feed SBR is to determine the feeding strategy for the amount of influent feeding in anoxic phase [27, 28]. However, most studies conducting research on parameters for controlling SBR performance have only focused on the oxidation-reduction potential (ORP), pH, DO, hydraulic retention time (HRT), operating cycle time, and reaction time [29-31]. In step feed SBR, the nitrate concentration at the beginning of the anoxic phase is determined by the residual ammonium concentration (extra carbon source) after the feeding phase, hence the introduced extra carbon source should be proportional to the nitrate concentration that can be removed under anoxic condition. On the other hand, the inappropriate volume of step feeding will lead to insufficient carbon source, which will cause slow denitrification rate, and also result in high concentration of effluent nitrogen. Therefore, this study optimizes the volumetric step-feeding ratio of extra carbon source in the anoxic phase of the SBR system.

Multi-attribute decision analysis (MADA) methods have been widely reported to be broadly applied in different processes for wastewater treatment fields. Hadipour et al. [32] developed a MADA method to rank the processes for wastewater reuse by employing the Analytical Hierarchy Process (AHP). Zorpas et al. [33] also employed MADA to investigate the processes for wastewater treatment in the field of winery. When decision problems involve large numbers of attributes and alternatives, TOPSIS (Technique for Order Preference by Similarity to Ideal Solution) is the preferred method, especially when objective or quantitative data are available [34]. It is also one of the most famous MADA tools in dealing with multi-attribute or multi-criteria decision-making problems in the real world, and its high flexibility enables it to be efficiently applicable in diverse situations [35]. Therefore, this study proposed entropy weight meth- od based TOPSIS for the optimization of influent feeding for the SBR.

The aim of this study is to investigate the effect of the influent step feeding on the nitrogen removal efficiency in the step-feeding SBR. The other objective of this study is to optimize the best condition of step feeding for SBR using the entropy-based TOPSIS method. In order to verify the nutrient removal properties using the proposed method, we compare the removal efficiency of nitrogen and phosphorus under different step feedings. The variation of nitrogen concentration of a single complete operating cycle on each step feeding was also analyzed to demonstrate the benefits of step feeding on nitrogen removal. Finally, the ideal influent feeding of the SBR was further investigated by comparing the theoretical result obtained from TOPSIS with the optimal step feeding condition under the real operation of the SBR.

\section{Materials and Methods}

\subsection{Wastewater Sources and Characteristics}

The feeding wastewater used in this study was the real municipal wastewater taken from the primary sedimentation tank in the wastewater treatment plant (Ansan, Korea). The characteristics of influent wastewater are as follows: chemical oxygen demand (COD) $84.52 \pm 13.7 \mathrm{mg} / \mathrm{L}$, biochemical oxygen demand (BOD) $119.45 \pm 19.36 \mathrm{mg} / \mathrm{L}$, TN $37.96 \pm 4.03 \mathrm{mg} / \mathrm{L}$, and total phosphorous (TP) $3.6 \pm 0.5 \mathrm{mg} / \mathrm{L}$. The average influent characteristic did not change significantly during different operating conditions.

\subsection{Operation Condition of SBR}

The pilot-scale SBR with a depth of $3.2 \mathrm{~m}$ and a working volume of $120 \mathrm{~m}^{3}$ (Fig. S1) was installed at a wastewater treatment plant (Ansan, Korea). In a given cycle time, the initial feeding, anoxic phase, aerobic phase, settling phase, and final discharge were included. The DO, pH, mixed liquor suspended solids (MLSS), oxidation-reduction potential (OPR), and electronic flowmeter were also installed to check the condition of the reactor. The MLSS concentration of the reactor was 2,530 $\pm 87 \mathrm{mg} / \mathrm{L}$. The internal circulation pipe with a flow rate of $2 \mathrm{~m} / \mathrm{s}$ was installed at the bottom of the reactor to enhance denitrification by circulating the supernatant into the settled sludge layer, to control DO concentration during the anoxic period. The program performed all of the operations automatically. To analyze the nutrient removal performance according to carbon source addition, three different influent feeding modes: one-step feeding, two-step feeding, and three-step feeding in one sequence operation of the SBR were performed (Fig. S2). The sequence time of each feeding mode was $360 \mathrm{~min}$.

\subsection{Analytical Methods.}

TN, TP, and COD were measured according to the Standard Method [36]. $\mathrm{NH}_{4}{ }^{+}-\mathrm{N}, \mathrm{NO}_{3}{ }^{-}-\mathrm{N}, \mathrm{NO}_{2}^{-}-\mathrm{N}$, and $\mathrm{PO}_{4}{ }^{3-}-\mathrm{P}$ were analyzed using ion chromatography (Metrohm, Compact IC 761). 
The removal efficiency was calculated as follows:

$$
\begin{gathered}
\text { Efficiency }= \\
\text { (Influent concentration }- \text { Effluent concentration) } / \\
\text { Influent concentration } \times 100 \%
\end{gathered}
$$

Empirical effluent concentration was also calculated as Eq. (2) presented in the previous work [21] with initial TN of $50 \mathrm{mg} / \mathrm{L}$, $\mathrm{N}$-removal/COD range 0.1 to 0.4 , total influent feeding of $40 \%$ of reactor working volume, and initial COD range 200 to 600 .

$$
\begin{gathered}
\mathrm{T}-\mathrm{N}(\mathrm{mg} / \mathrm{L})=\left(\mathrm{C}_{\mathrm{EffNO}-} \mathrm{N}_{\mathrm{COD}} \times \mathrm{COD}_{\mathrm{O}} \times \mathrm{F}_{1}\right)+ \\
{\left[\left[\left(\mathrm{C}_{\mathrm{Effam}}+\mathrm{C}_{\mathrm{am} 0}\right) \times \mathrm{F}_{1} \times\left(\mathrm{N}_{\mathrm{oxi}}\right)-\mathrm{N}_{\mathrm{COD}} \times \mathrm{COD}_{\mathrm{O}} \times \mathrm{F}_{2}\right]+\right.} \\
\left.\mathrm{C}_{\mathrm{am} 0} \times \mathrm{F}_{2} \times\left(\mathrm{N}_{\mathrm{oxi}}\right)\right]-\left[\mathrm{N}_{\mathrm{COD}} \times \mathrm{COD}_{\mathrm{O}} \times \mathrm{F}_{3}\right]+ \\
\mathrm{C}_{\mathrm{am0} 0} \mathrm{x} \mathrm{F}_{3} \times\left(\mathrm{N}_{\mathrm{oxi}}\right)
\end{gathered}
$$

$\mathrm{C}_{\mathrm{EffNO} 3}=$ Effluent $\mathrm{NO}_{3}{ }^{-} \mathrm{-}$ concentration from previous stage

$\mathrm{C}_{\text {effam }}=$ Effluent $\mathrm{NH}_{4}{ }^{+}-\mathrm{N}$ concentration from previous stage

$\mathrm{C}_{\mathrm{am} 0}=$ Initial concentration of ammonia

$\mathrm{N}_{\mathrm{COD}}=$ Denitrification rate per COD

$\mathrm{N}_{\text {oxi }}=$ Nitrification rate

$\mathrm{COD}_{\mathrm{O}}=$ Initial COD

$\mathrm{F}_{1} \quad=$ ratio of first feeding of raw wastewater

$\mathrm{F}_{2} \quad=$ ratio of second feeding of raw wastewater

$\mathrm{F}_{3} \quad=$ ratio of third feeding of raw wastewater

\subsection{Entropy Weight Based TOPSIS Method}

TOPSIS was initially proposed by Hwang and Yoon in 1981 [37]. The fundamental principle of TOPSIS is that the best alternative should have the shortest Euclidean distance from the positive ideal solution, and the farthest distance from the negative ideal solution [38]. In our work, the optimal condition of volumetric influent step feeding of SBR was determined using TOPSIS. The process of TOPSIS is presented as follows:

Establish decision matrix using Eq. (3):

$$
X=\left[X_{i j}\right]=\left[\begin{array}{cccc}
x_{11} & x_{12} & \cdots & x_{1 n} \\
x_{21} & x_{22} & \cdots & x_{2 n} \\
\vdots & \vdots & \ddots & \vdots \\
x_{m 1} & x_{m 2} & \cdots & x_{m n}
\end{array}\right]
$$

For every alternative $i,(i=1, \ldots, \mathrm{m})$, there exist a corresponding criterion $j,(j=1, \ldots, \mathrm{n})$, and the value of the $\mathrm{i}$ th alternative with respect to the $\mathrm{j}$ th criterion is denoted as $\mathrm{X}_{i j} . \mathrm{X}_{\mathrm{ij}}$ is known as the performance value of each alternative.

The next step is normalization of the decision matrix as in Eq. (4):

$$
y_{i j}=X_{i j} / \sqrt{\sum_{j=1}^{m} X_{i j}^{2}}
$$

The weighted decision matrix can be obtained by multiplication of the normalized decision matrix by the weights of the indices.

$$
V_{i j}=w_{j} y_{i j}
$$

In this step, the weight $\left(w_{j}\right)$ of each criteterion was determined using the Entropy weight method. Entropy was introduced by Shanon, and is widely applied in engineering, medicine, and eco- nomics to solve decision-making problems [39]. The entropy method is an objective weighting method based on the principle that greater uncertainty about outcomes results in a more uniform probability assigned to them [40]. The entropy weight method is used in this study, because it not only removes the subjectivity of the decision-maker in determining the weights but is also very useful in the cases when experts conflict on the values of weights, which ensures that it is more objective and credible than the subjective methods for comprehensive evaluation of the multivariate index [41, 42].

The principles of the entropy method are as follows:

The raw data of the indicators are taken as an $m \times n$ matrix, where $m$ is defined as the number of evaluation objects, and $n$ indicates the number of indicators. A decision matrix is established using Eq. (3):

The second step is normalization of the decision matrix as in Eq. (6):

$$
y_{i j}=x_{i j} / \sum_{i=1}^{m} x_{i j}
$$

The entropy value, $e_{j}$ for the $j^{\text {th }}$ indicator is calculated as:

$$
e_{j}=-\mathrm{h} \sum_{i=1}^{m} y_{i j} \ln y_{i j}
$$

where, $\mathrm{h}=\frac{1}{\ln (m)}$, and $\mathrm{m}=$ the number of alternatives.

Finally, the objectives weight $w_{j}$ for each criterion can be computed as Eq. (8):

$$
w_{j}=\frac{1-e_{j}}{\sum_{j=1}^{n} 1-e_{j}}
$$

Then, determine the positive ideal solution $\mathrm{V}^{+}$and the negative ideal solution $\mathrm{V}^{-}$

$$
\begin{aligned}
& \mathrm{V}^{+}=\left\{\left(\max \mathrm{V}_{\mathrm{ij}} \mid \mathrm{J}, \mathrm{i}=1,2, \ldots ., \mathrm{m}\right\}=\right. \\
& \left\{\mathrm{V}_{1}{ }^{+}, \mathrm{V}_{2}{ }^{+}, \ldots ., \mathrm{V}_{\mathrm{n}}{ }^{+}\right\} \\
& \mathrm{V}^{-}=\left\{\left(\min \mathrm{V}_{\mathrm{ij}} \mid \mathrm{J}, \mathrm{i}=1,2, \ldots, \mathrm{m}\right\}=\right. \\
& \left\{\mathrm{V}_{1}^{-}, \mathrm{V}_{2}^{-}, \ldots, \mathrm{V}_{\mathrm{n}}^{-}\right\}
\end{aligned}
$$

The Euclidean distances from the best ideal solution and the worst ideal solution are calculated using Eq. (11) and (12), respectively:

$$
\begin{aligned}
& S^{+}=\sqrt{\sum_{j}^{m}\left(V_{i j}-V_{j}^{+}\right)^{2}} \\
& S^{-}=\sqrt{\sum_{j}^{m}\left(V_{i j}-V_{j}^{-}\right)^{2}}
\end{aligned}
$$

The relative closeness to the ideal solution is calculated using Eq. (13):

$$
\mathrm{C}_{\mathrm{i}}=\frac{S_{i}^{-}}{S_{i}^{+}+S_{i}^{-}}
$$

where, the $C_{i}$ value ranges 0 to 1 . The ideal solution having the largest $C_{i}$ represents the optimal solution. In our work, we define the ideal solution as the optimum influent step feeding with the 
lowest effluent nitrogen concentration corresponding to different $\mathrm{C} / \mathrm{N}$ ratios under various biological nitrogen removal ratios (N-removal/COD).

\section{Results and Discussion}

\subsection{Performance of the SBR}

The operation of the SBR was observed during the study period of 94 days covering three different experimental runs: one-step influent feeding, two-step influent feeding, and three-step influent feeding. The operation strategy applied to the SBR was as follows: anoxic filling, aeration, settling, and final discharge. When the step-feeding mode was performed, influent wastewater as extra carbon source was added to the anoxic phase of the operating cycle. During this period, the average influent nitrogen concentration fluctuated in the narrow range of $33.9-41.9 \mathrm{mg} / \mathrm{L}$. It was observed that under the aerobic condition, $\mathrm{NH}_{4}{ }^{+}-\mathrm{N}$ decreased, whereas, as the ammonia was oxidized by nitrification, there was an increase of $\mathrm{NO}_{2}^{-}-\mathrm{N}$ and $\mathrm{NO}_{3}^{-}-\mathrm{N}$ concentration. The system achieved the highest nitrogen removal rate of over $92 \%$ under the three-step influent feeding mode, with the average effluent total nitrogen concentration as low as $2 \mathrm{mg} / \mathrm{L}$. This high nitrogen removal efficiency was achieved as a result of step-feeding sufficiently providing the required carbon source for denitrification. These results show that there was a significant relation between the denitrification performance and the feeding of extra carbon sources.

\subsection{Nitrogen Variation with Step Feeding of Raw Wastewater during a Single Operating Cycle}

Fig. 1 shows the variation of nitrogen and phosphorus concentration of a sequence cycle in different step feeding. The feeding wastewater was $40 \%$ of the working volume of the reactor, and the operation period was $360 \mathrm{~min}$. In our work, the anoxic and aerobic durations were controlled by real-time systems, which to ensure nitrification and denitrification proceeded completely, could flexibly determine each duration. As the figure shows, the ammonia concentration was altered according to the step feeding. When there was no extra feeding of influent (Fig. 1(a)), the denitrification performance was low in this step, due to the lack of required carbon source to further oxidize nitrate, hence resulting in high concentration of effluent nitrogen. Generally, most denitrifying bacteria are heterotrophic, and therefore require organic carbon source for cell growth and nitrate reduction [43]. It has been reported that carbon sources significantly affect the removal of nitrate in the denitrification process, and also enhance the overall nutrient removal performance [44, 45].

In order to improve the denitrification process, raw wastewater as carbon source was added in anoxic phases during two-step feeding mode (Fig. 1(b)) and three-step feeding mode (Fig. 1(c)). In the two-step feeding mode, $70 \%$ of the total amount of feeding wastewater was introduced in the first anoxic feeding, followed by the remaining $30 \%$ being supplied in the next anoxic process (Fig. 1(b)). The ammonia concentration was increased in the initial anoxic condition, and also in the second anoxic condition. This ammonia variation pattern confirmed that the ammonia containing wastewater was supplied in the $2^{\text {nd }}$ feeding. The final $\mathrm{NO}_{3}^{-}-\mathrm{N}$ concentration
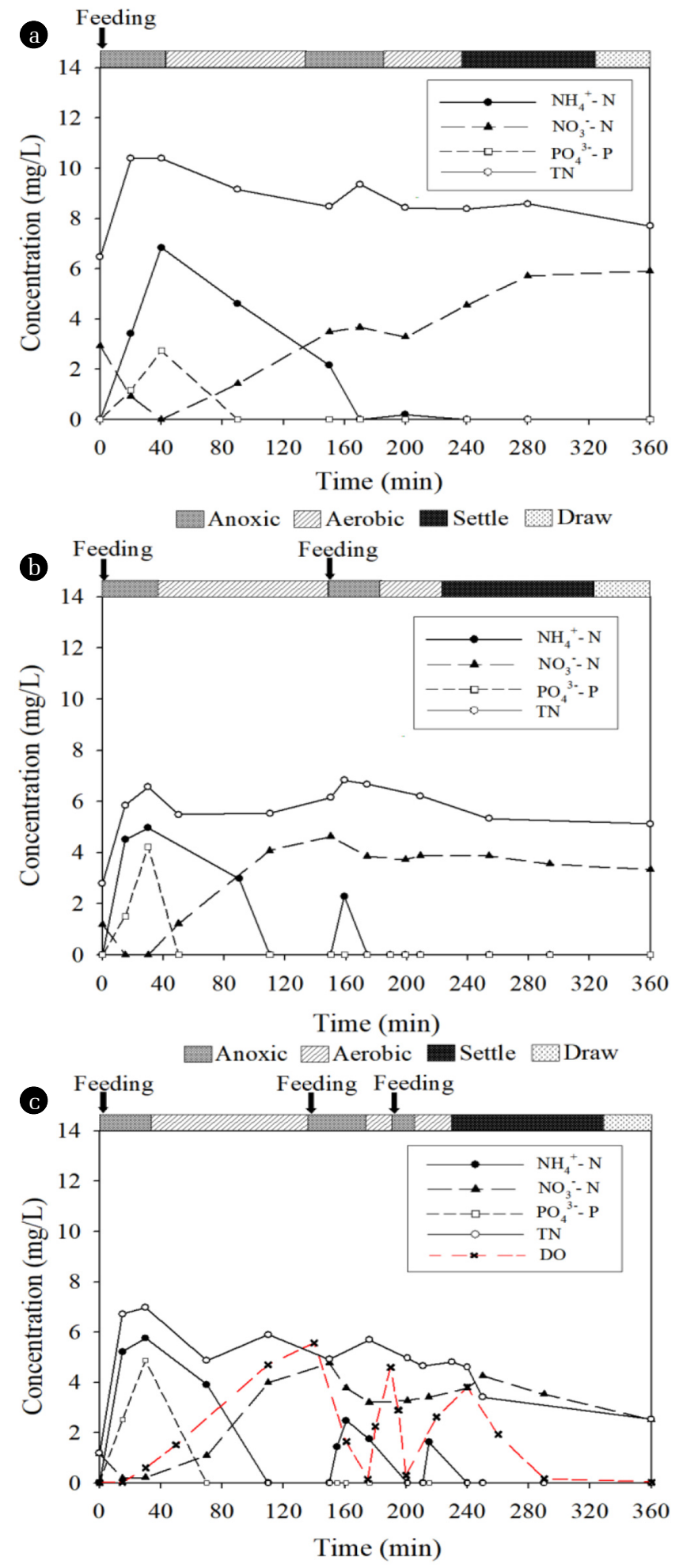

Anoxic Aerobic Settle 5 Draw

Fig. 1. Variation of $\mathrm{NH}_{4}{ }^{+}-\mathrm{N}, \mathrm{NO}_{3}{ }^{-}-\mathrm{N}$, and $\mathrm{PO}_{4}{ }^{3-}-\mathrm{P}$ concentration during one complete cycle under different step feeding modes in SBR: (a) One-step feeding, (b) Two-step feeding, and (c) Three-step feeding. 
was relatively lower compared with the one-step feeding mode, which indicates that the denitrification process was improved. The three-step feeding mode with anoxic feeding was carried out to further enhance nitrogen removal, with $60 \%$ primary influent feeding, 30\% secondary feeding, followed by $10 \%$ tertiary feeding of the total amount of feeding wastewater (Fig. 1(c)). Similar to the previous feeding mode, the ammonia variation observed under anoxic conditions confirmed that the carbon source was added in the $3^{\text {rd }}$ feeding. The decrease of DO during the anoxic feeding process and simultaneously increased until the end of the aerobic stage also shows that both nitrification and denitrification proceeded well under the corresponding anoxic and aerobic conditions, thereby improving the nutrient removal efficiency. In this mode, the denitrification was further enhanced, as the carbon source required for the removal of nitrate was supplied by the $3^{\text {rd }}$ feeding. Low $\mathrm{NO}_{3}{ }^{-} \mathrm{N}$ concentration was also observed at the end of the cycle. This clearly demonstrates the benefits of extra carbon source feeding in the removal of nutrients in the SBR system.

When the required carbon source was supplied in the two-step and three-step feeding modes, the $\mathrm{PO}_{4}{ }^{3-}-\mathrm{P}$ removal was also improved. When there was not sufficient carbon source to remove the nitrate-nitrogen in the one-step feeding mode, the remaining nitrate inhibited phosphate release and uptake, which caused low removal efficiency. This result was consistent with the previous work conducted in lab-scale experiments, which revealed that the presence of nitrate inhibited phosphate release and uptake [21]. It has also been reported that nitrite could severely inhibit the anoxic phosphate uptake and the anaerobic phosphate release by the polyphosphate accumulating organisms (PAOs) in enhanced biological phosphorus removal (EBPR) processes [46, 47].

\subsection{TN and TP Removal Efficiency of the SBR According to the Step Feeding of Raw Wastewater}

Fig. 2 shows the removal efficiency of TN and TP concentration at different influent step feeding modes. The study consists of three phases: one-step feeding (Days 1-14), two-step feeding (Days 15-59), and three-step feeding (Days 60-94). The TN and TP concentrations of influent and effluent were measured once a day. The removal efficiencies of TN and TP were calculated using Eq. (1). Fig. 2 shows that the step feeding of influent influenced the removal efficiency of both TN and TP. Fig. 2(a) shows that the TN removal efficiency in the three-step feeding was significantly higher than those in the one-step and two-step feedings. The average removal efficiencies of TN for the one-step, two-step, and three-step feedings were 68.7 , 85.3, and $92.7 \%$, respectively. Since the highest TN removal efficiency was observed in three-step feeding, it could be concluded that the low TN removal rates at the one-step feeding mainly resulted from a deficiency in the carbon source required for nitrate removal. Wang et al. [22] and Guo et al. [25] also observed that increase in step-feeding with carbon sources could promote the TN removal performance. Similarly, increased step-feeding also increased TP removal (Fig. 2(b)).

The removal efficiencies of TP for the one-step, two-step, and three-step feedings were $76.4,79.8$, and $94.2 \%$, respectively. The results indicate that the addition of carbon sources also helped to improve the removal of TP. These findings indicate that the

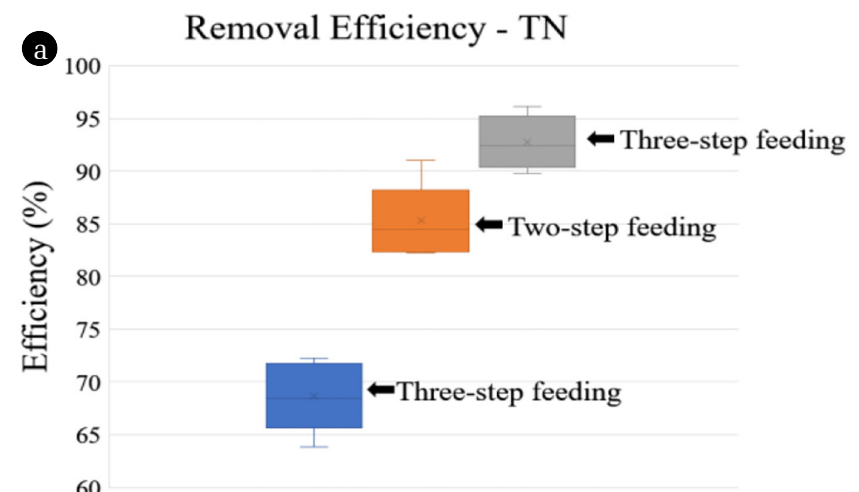

Removal Efficiency - TP

b) ${ }^{100}$

Fig. 2. (a) Removal efficiency of $\mathrm{TN}$, and (b) Removal efficiency of TP with the step feeding of influent to the SBR.

anoxic condition with sufficient carbon source by adding raw influent step-feeding significantly improved the denitrification process, revealing the advantages of influent step addition feeding in the SBR. The same result was also observed in the previous work [21], which showed that the three-step influent feeding mode achieved a faster denitrification rate and lower effluent nitrogen concentration.

\subsection{Effect of the Biological Nitrogen Removal Ratio based on COD (N-removal/COD) in the Step Feeding Process}

In order to calculate the optimum influent step feeding in the presence of various $\mathrm{C} / \mathrm{N}$ ratios, the effluent nitrogen concentration was calculated using Eq. (2) considering the N-removal/COD ratio range 0.1 to 0.3 . The three-step influent feeding mode was selected for this effluent calculation. The $1^{\text {st }}$ influent feeding was initially considered from 10 to $70 \%$, the $2^{\text {nd }}$ feeding range from 20 to $50 \%$, and the $3^{\text {rd }}$ feeding range from 10 to $70 \%$. Moreover, the $\mathrm{C} / \mathrm{N}$ ratio was also divided into five: $1.5,2.25,3,3.75$, and 4.5.

Fig. 3 shows that the effluent concentration varies according to the $\mathrm{C} / \mathrm{N}$ ratio, and the adding volume of the influent. Generally, as our calculation progressed towards higher $\mathrm{C} / \mathrm{N}$ and $\mathrm{N}-\mathrm{re}-$ moval/COD, the effluent concentrations become lower for each feeding volume. Fig. 3(a) shows that when the N-removal/COD value was 0.1 , the lowest effluent concentration could be found with the $1^{\text {st }}, 2^{\text {nd }}$, and $3^{\text {rd }}$ feeding of 40,30 , and $30 \%$ under influent with $\mathrm{C} / \mathrm{N}$ of 4.5 . However, the effluent concentration of $\mathrm{TN}$ in this mode is relatively high. When the $\mathrm{N}$-removal/COD value was 
N-removal/COD - 0.1

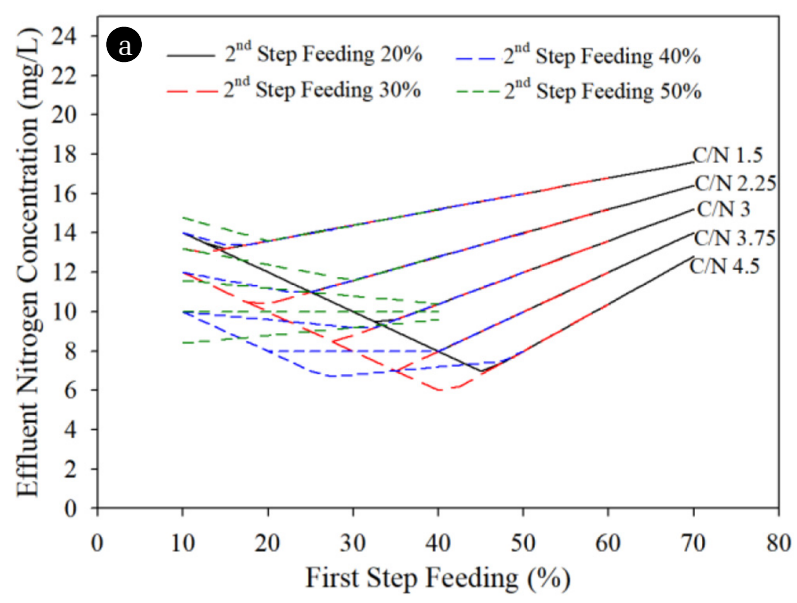

N-removal/COD - 0.25

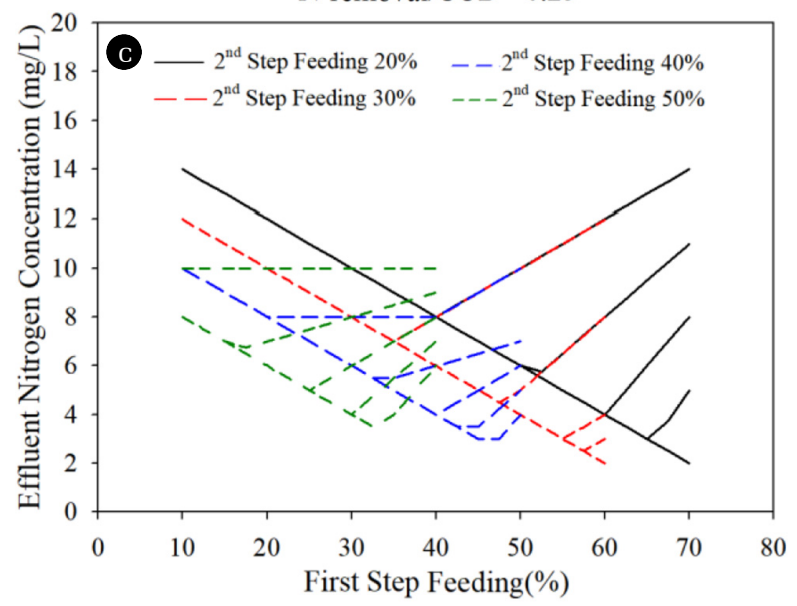

N-removal/COD - 0.2

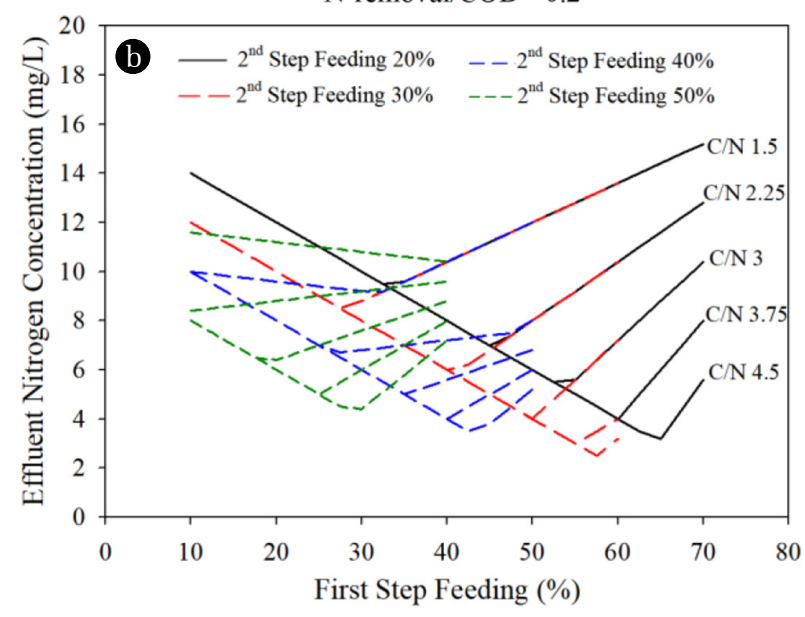

N-removal/COD -0.3

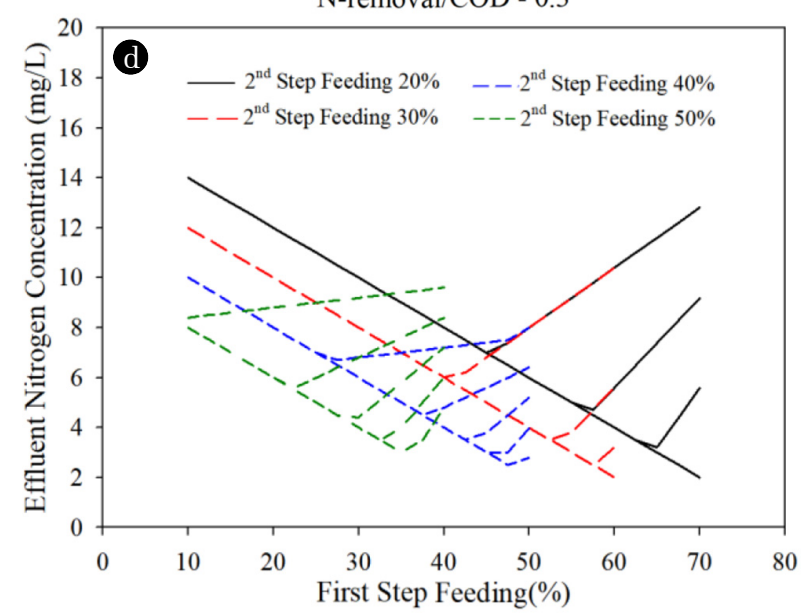

Fig. 3. Effluent concentration of nitrogen with different $\mathrm{C} / \mathrm{N}$ ratio and three-step feeding of the influent according to the biological nitrogen removal ratio based on COD (N-removal/COD): (a) N-removal/COD - 0.1, (b) N-removal/COD - 0.2, (c) N-removal/COD - 0.25, (d) $\mathrm{N}$-removal $/ \mathrm{COD}-0.3: 3^{\text {rd }}$ Step feeding $=100 \%-\left(1^{\text {st }}\right.$ Step Feeding $+2^{\text {nd }}$ Step Feeding $)$

increased to 0.2 (Fig. 3(b)), the effluent decreased sharply with $\mathrm{C} / \mathrm{N}$ ratio of 4.5 . In this step, the optimum step feeding volume could be found with $30 \%$ of $2^{\text {nd }}$ feeding. The optimum step feeding with the lowest effluent concentration was observed when the $\mathrm{N}$-removal/COD approached 0.25 (Fig. 3(c)), with three-step feeding as 60,30 , and $10 \%$, respectively. Similar to previous observations, the $\mathrm{C} / \mathrm{N}$ value for this condition was 4.5 . In addition, it is noteworthy that when the $\mathrm{N}$-removal/COD value was increased to 0.3 , the optimum step feeding ratio and the effluent concentration were not significantly changed (Fig. 3(d)). Therefore, under the condition with the $\mathrm{C} / \mathrm{N}$ ratio range 0.1 to 4.5 , our findings indicate that the optimum three-step influent feeding was 60 , 30, and $10 \%$ with the effluent nitrogen concentration as low as $2 \mathrm{mg} / \mathrm{L}$. Moreover, the results further showed that the carbon source required in denitrification could be provided sufficiently with COD contained in the influent wastewater with $\mathrm{C} / \mathrm{N}$ of 4.5. However, even though the optimum influent step feeding volume could be obtained from these findings (Fig. 3), the analysis was inadequate, especially if additional parameters and variables were considered and there was a large fluctuation of the influent nitrogen concentration. For this reason, the multi-criteria decision-making tool TOPSIS with entropy weight method was applied to further confirm the precision of the optimum influent step feeding method.

\subsection{Optimization of Influent Step Feeding for the SBR Using TOPSIS}

Table 1 presents the performance value matrix of the nitrogen effluent concentration for the selection of optimum influent step feeding. This table forms our original matrix table consisting of alternatives and criteria that represent our initial matrix, as described in Eq. (3). The effluent nitrogen concentration of this matrix is calculated using Eq. (2). The three-step influent feeding mode was selected for this effluent calculation. The criteria for the selection of the optimum step feeding of the SBR considered in this study are the $\mathrm{C} / \mathrm{N}$ ratios $2.25,3,3.75$, and 4.5 with the $\mathrm{N}$-removal/COD rate divided into four, $0.1,0.2,0.3$, and 0.4 . In the table, Case $(\mathrm{x}, \mathrm{y}, \mathrm{z})$ refers to the volume (\%) of the influent feeding in primary, 


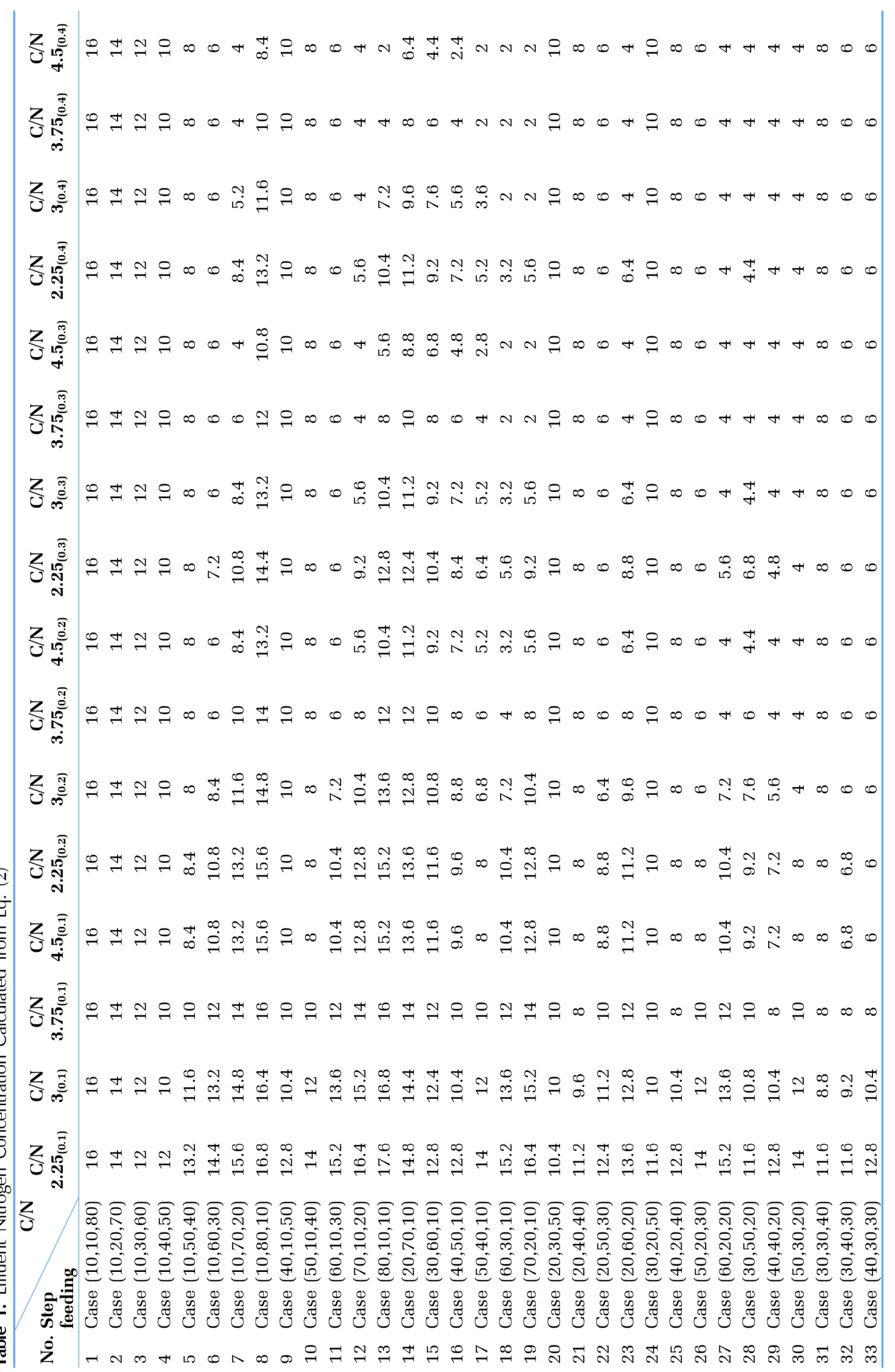

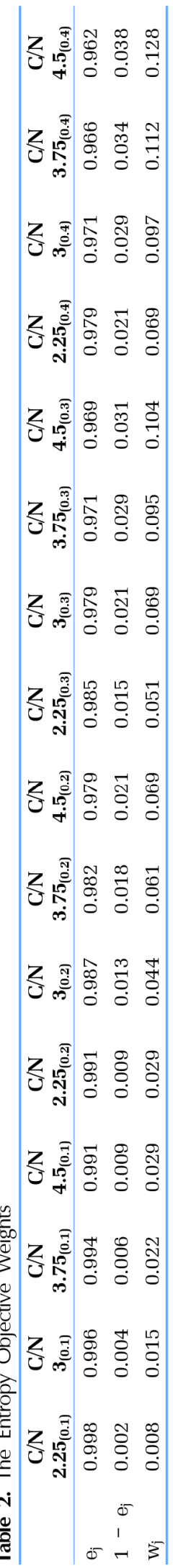


secondary, and tertiary anoxic phase (i.e., 10\% primary feeding, $10 \%$ secondary feeding, $80 \%$ tertiary feeding). The acronym C/N $(\mathrm{x})_{(\mathrm{y})}$ stands for the initial influent $\mathrm{C} / \mathrm{N}$ ratio under the corresponding N-removal/COD rate. The objective weights $\left(w_{j}\right)$ for each criterion were calculated using the entropy weight method, and Table 2 presents the results. The weights of each criterion obtained from the entropy method were used in the implementation of TOPSIS optimization. The normalized decision matrix was computed as Eq. (4) using vector normalization. The vector normalization method has been employed for normalization, as when applied to TOPSIS, it is proven to minimize the chances of rank reversal [37, 48, 49]. Then, the weights of each criterion obtained from the entropy method were used to compute the weighted normalized decision matrix using Eq. (5). After that, the Euclidean distances from the best ideal solution and the worst ideal solution $\left(\mathrm{S}^{+}, \mathrm{S}^{-}\right)$, the relative closeness of the ideal solution $\left(\mathrm{C}_{\mathrm{i}}\right)$, and the TOPSIS ranking of each criterion were calculated, and Table 3 shows them.
Table 3 shows that the influent step feeding with the relative closeness score close to 1.0 represents the ideal best solution, while the farthest from 1.0 represents the ideal worst solution. Table 4 also shows the top 10 rankings of the influent step feeding for the SBR calculated from TOPSIS. The three-step feeding mode of $60 \%$ of $1^{\text {st }}$ feeding, $30 \%$ of $2^{\text {nd }}$ feeding, and $10 \%$ of $3^{\text {rd }}$ feeding (i.e., Case $60,30,10$ ) with a relative closeness score of 0.958 was ranked closest to the ideal solution. In addition, an interesting observation is that the optimum step feeding achieved from TOPSIS was consistent with our previous results from Fig. 3, in which the optimal step feeding was also 60,30 , and $10 \%$. Moreover, the real-time average effluent nitrogen concentration of three-step feeding with 60:30:10 from the pilot plant is 2.77 $\mathrm{mg} / \mathrm{L}$, which is close to our theoretical findings. Furthermore, in our previous work [37], the optimum step feeding was also obtained in the three-step feeding mode as 60:30:10, by using the $\mathrm{N}$-removal/COD value 0.2 measured from the experimental results of $\mathrm{N}$ and COD concentration. These results have further

Table 3. The Closeness Coefficient $\mathrm{S}^{-}, \mathrm{S}^{+}$, Relative Closeness $\mathrm{C}_{\mathrm{i}}$, and TOPSIS Ranking Order of Each Influent Step Feeding

\begin{tabular}{|c|c|c|c|c|c|}
\hline No. & Step feeding & $\mathbf{S}^{-}$ & $\mathbf{S}^{+}$ & $\mathrm{C}_{\mathrm{i}}$ & Ranking \\
\hline 1 & Case $(10,10,80)$ & 0.008 & 1.575 & 0.005 & 33 \\
\hline 2 & Case $(10,20,70)$ & 0.379 & 1.197 & 0.241 & 32 \\
\hline 3 & Case $(10,30,60)$ & 0.707 & 0.869 & 0.449 & 31 \\
\hline 4 & Case $(10,40,50)$ & 0.985 & 0.592 & 0.625 & 28 \\
\hline 5 & Case $(10,50,40)$ & 1.210 & 0.366 & 0.768 & 23 \\
\hline 6 & Case $(10,60,30)$ & 1.376 & 0.206 & 0.870 & 16 \\
\hline 7 & Case $(10,70,20)$ & 1.396 & 0.267 & 0.839 & 17 \\
\hline 8 & Case $(10,80,10)$ & 0.868 & 0.792 & 0.523 & 30 \\
\hline 9 & Case $(40,10,50)$ & 0.985 & 0.592 & 0.625 & 29 \\
\hline 10 & Case $(50,10,40)$ & 1.211 & 0.366 & 0.768 & 22 \\
\hline 11 & Case $(60,10,30)$ & 1.380 & 0.201 & 0.873 & 15 \\
\hline 12 & Case $(70,10,20)$ & 1.464 & 0.174 & 0.894 & 9 \\
\hline 13 & Case $(80,10,10)$ & 1.324 & 0.416 & 0.761 & 24 \\
\hline 14 & Case $(20,70,10)$ & 1.100 & 0.537 & 0.672 & 25 \\
\hline 15 & Case $(30,60,10)$ & 1.292 & 0.332 & 0.795 & 18 \\
\hline 16 & Case $(40,50,10)$ & 1.438 & 0.177 & 0.890 & 10 \\
\hline 17 & Case $(50,40,10)$ & 1.529 & 0.072 & 0.955 & 3 \\
\hline 18 & Case $(60,30,10)$ & 1.565 & 0.068 & 0.958 & 1 \\
\hline 19 & Case $(70,20,10)$ & 1.523 & 0.161 & 0.904 & 7 \\
\hline 20 & Case $(20,30,50)$ & 0.985 & 0.592 & 0.625 & 26 \\
\hline 21 & Case $(20,40,40)$ & 1.212 & 0.365 & 0.768 & 20 \\
\hline 22 & Case $(20,50,30)$ & 1.384 & 0.193 & 0.878 & 14 \\
\hline 23 & Case $(20,60,20)$ & 1.459 & 0.158 & 0.902 & 8 \\
\hline 24 & Case $(30,20,50)$ & 0.985 & 0.592 & 0.625 & 27 \\
\hline 25 & Case $(40,20,40)$ & 1.211 & 0.365 & 0.768 & 21 \\
\hline 26 & Case $(50,20,30)$ & 1.385 & 0.192 & 0.878 & 13 \\
\hline 27 & Case $(60,20,20)$ & 1.501 & 0.096 & 0.940 & 6 \\
\hline 28 & Case $(30,50,20)$ & 1.493 & 0.093 & 0.941 & 5 \\
\hline 29 & Case $(40,40,20)$ & 1.508 & 0.070 & 0.956 & 2 \\
\hline 30 & Case $(50,30,20)$ & 1.510 & 0.073 & 0.954 & 4 \\
\hline 31 & Case $(30,30,40)$ & 1.212 & 0.365 & 0.768 & 19 \\
\hline 32 & Case $(30,40,30)$ & 1.387 & 0.190 & 0.879 & 12 \\
\hline 33 & Case $(40,30,30)$ & 1.387 & 0.190 & 0.879 & 11 \\
\hline
\end{tabular}




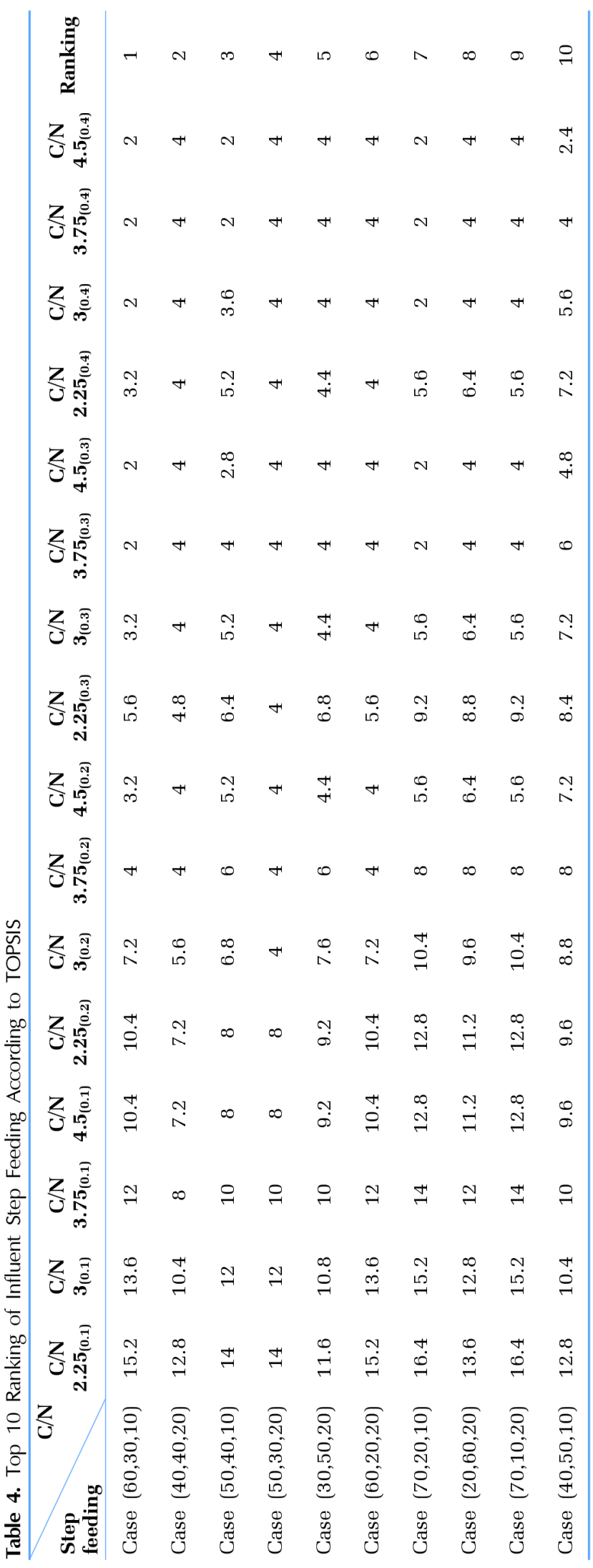

strengthened our confidence that TOPSIS has the potential ability to determine the ideal influent step feeding.

This study proposed the application of the entropy weight method based TOPSIS approach for the first time in the optimization of volumetric influent step feeding for nitrogen removal in the SBR system. In this study, we obtained the same condition of optimum step feeding of 60,30 , and $10 \%$ in both TOPSIS and the result we obtained from Fig. 3. However, when more parameters are considered for the optimization or larger data fluctuation depending on decision-makers is preferred, the optimum condition of influent step feeding can be changed. In such cases, optimization of the influent feeding just by using figures is insufficient and unsatisfactory. Decision-making by mathematical optimization, such as TOPSIS, is superior and more precise; hence in this study, the TOPSIS method is proposed. The TOPSIS method has no special data restrictions of the evaluation criteria under the study, which make it easy to understand the advantages of the application [50]. The method also avoids the subjectivity of weight determination, with no excessive requirement of the data sample. This is beneficial to analyzing the optimum condition for influent step feeding in this work, where the data has a large fluctuation of nitrogen concentration under corresponding $\mathrm{C} / \mathrm{N}$ ratios, $\mathrm{N}$-removal/COD, and objectively and thoroughly reflects the dynamic change trend of decision-makers preferences and influent nitrogen concentration.

Although our previous work [21] has also obtained optimum condition of volumetric influent feeding, the observations only consider N-removal/COD of 0.2. This is not strong enough to determine the optimum influent feeding, especially in wastewater treatment using the SBR system, which has a large variety of organic matter composition that could greatly affect the nutrient treatment efficiency. The TOPSIS method could easily determine the optimum condition of influent feeding, even with the large data fluctuation of organic matter. The optimization results clearly show that TOPSIS could easily determine the optimal volumetric feeding of external carbon sources, regardless of various influent loading conditions. The significance of our study lies in the application of TOPSIS that could precisely determine the optimum condition of the influent step feeding ratio in the SBR system, and give relevant outcomes, regardless of the various step feeding conditions, complicated parameters, and decision-makers preferences. This approach could also be applied for optimization of the influent step feeding in the SBR system, even when decision-makers consider additional factors, such as energy consumption and cost-efficiency.

\section{Conclusions}

The nitrogen variation analysis of a single complete cycle showed that the highest denitrification rate was achieved in the three-step feeding mode with $60 \%$ primary feeding, $30 \%$ secondary feeding, followed by $10 \%$ tertiary feeding. For one-step, two-step, and three-step addition modes, the removal efficiencies of TN and TP were $68.7,85.3$, and $92.7 \%$ and $76.4,79.8$, and $94.2 \%$, respectively. The results demonstrate that the removal efficiencies of TN increased with increasing feeding step, revealing that the feeding of the influent carbon source acts as an important parameter in the nutrient removal process of SBR. The TOPSIS analysis shows 
that the optimum three-step feeding mode was 60 , 30, and $10 \%$, with the highest relative closeness score $\left(\mathrm{C}_{\mathrm{i}}\right)$ of 0.958 . In conclusion, the results obtained from this study provide significant insights that show the optimum influent step feeding ratio of SBR with three-step feeding mode in primary, secondary, and tertiary anoxic phase was 60,30 , and $10 \%$ respectively. We believe that our research will serve as an important role for future studies of the optimization of influent step feeding of the SBR system.

\section{Author Contributions}

N.Z.L.M. (M.Sc. student) conducted all the experiments, analyzed the data, and wrote the manuscript. Y.H. (Assistant Professor) contributed to the design of the experiment and implementation of the research. T.J.L. (Professor) led the overall research as a corresponding author, supervised the student, and revised the manuscript.

\section{References}

1. Duan H, Tao M, Loiselle SA, et al. MODIS observations of cyanobacterial risks in a eutrophic lake: Implications for long-term safety evaluation in drinking-water source. Water. Res. 2017;122:455-470.

2. Li Y, Zou J, Zhang L, Sun J. Aerobic granular sludge for simultaneous accumulation of mineral phosphorus and removal of nitrogen via nitrite in wastewater. Bioresour. Technol. 2014;154:178-184.

3. Yang L, Lei K, Meng W, Fu G, Yan W. Temporal and spatial changes in nutrients and chlorophyll- $\alpha$ in a shallow lake, Lake Chaohu, China: An 11-year investigation. J. Environ. Sci. 2013;25(6): 1117-1123.

4. Ahn JH, Kim S, Park H, Rahm B, Pagilla K, Chandran K. $\mathrm{N}_{2} \mathrm{O}$ Emissions from activated sludge processes, 2008-2009: Results of a national monitoring survey in the United States. Environ. Sci. Technol. 2010;44:4505-4511.

5. Lin Z, Wang Y, Huang W, et al. Single-stage denitrifying phosphorus removal biofilter utilizing intracellular carbon source for advanced nutrient removal and phosphorus recovery. Bioresour. Technol. 2019;277:27-36.

6. Daverey A, Su SH, Huang YT, Lin JG. Nitrogen removal from optoelectronic wastewater using the simultaneous partial nitrification, anaerobic ammonium oxidation and denitrification (SNAD) process in sequencing batch reactor. Bioresour. Technol. 2012;113:225-231.

7. Zhang QH, Yang WN, Ngo HH, et al. Current status of urban wastewater treatment plants in China. Environ. Int. 2016;92-93:11-22.

8. Bassin JP, Dezotti M, Sant'Anna Jr GL. Nitrification of industrial and domestic saline wastewaters in moving bed biofilm reactor and sequencing batch reactor. J. Hazard. Mater. 2011;185:242-248.

9. Du R, Peng Y, Cao S, et al. Advanced nitrogen removal with simultaneous Anammox and denitrification in sequencing batch reactor. Bioresour. Technol. 2014;162:316-322.

10. Liu YQ, Moy B, Kong YH, Tay JH. Formation, physical character- istics and microbial community structure of aerobic granules in a pilot-scale sequencing batch reactor for real wastewater treatment Enzyme. Microbial. Technol. 2010;46:520-525.

11. Yang Q, Gu SB, Peng YZ, Wang SY, Liu XH. Progress in the development of control strategies for the SBR process. Clean Soil Air Water. 2010;38:732-749.

12. Zhao W, Zhang Y, Lv D, Wang M, Peng Y, Li B. Advanced nitrogen and phosphorus removal in the pre-denitrification anaerobic/anoxic/aerobic nitrification sequence batch reactor (pre- $\mathrm{A}_{2} \mathrm{NSBR}$ ) treating low carbon/nitrogen $(\mathrm{C} / \mathrm{N})$ wastewater. Chem. Eng. J. 2016;302:296-304.

13. Ghehi TJ, Mortezaeifar S, Gholami M, Kalantary RR, Mahvi AH. Performance evaluation of enhanced SBR in simultaneous removal of nitrogen and phosphorous. J. Environ. Heal. Sci. Eng.2014;12:134.

14. Marin JCA, Caravelli AH, Zaritzky NE. Nitrification and aerobic denitrification in anoxic-aerobic sequencing batch reactor. Bioresour. Technol. 2016;200:380-387.

15. Chen FY, Liu YQ, Tay JH, Ning P. Operational strategies for nitrogen removal in granular sequencing batch reactor. $J$. Hazard. Mater. 2011;189:342-348.

16. Shi YJ, Wang XH, Yu HB, et al. Aerobic granulation for nitrogen via nitrite in a sequencing batch reactor and the emission of nitrous oxide. Bioresour. Technol. 2011;102:2536-2541.

17. Boog J, Nivala J, Aubron T, Mothes S, van Afferden M, Muller RA. Resilience of carbon and nitrogen removal due to aeration interruption in aerated treatment wet-lands. Sci. Total Environ. 2018;621:960-969.

18. Hocaoglu SM, Insel G, Cokgor EU, Orhon D. Effect of low dissolved oxygen on simultaneous nitrification and denitrification in a membrane bioreactor treating black water. Bioresour. Technol. 2011;102:4333-4340.

19. Man Y, Shen WH, Chen XQ, Long Z, Corriou JP. Dissolved oxygen control strategies for the industrial sequencing batch reactor of the wastewater treatment process in the papermaking industry. Environ. Sci. Water. Res. 2018;4:654-662.

20. Rassamee V, Sattayatewa C, Pagilla K, Chandran K. Effect of oxic and anoxic conditions on nitrous oxideemissions from nitrification and denitrification processes. Biotechnol. Bioeng. 2011;108:2036-2045.

21. Lee P, Lee D, Kim B, Hwang Y, Lee T. A study on the improvement of nitrogen \& phosphorus removal of sequence batch reactor with internal circulation and multi-step addition. J. Korea. Soc. Environ. Eng. 2020;42:280-288.

22. Wang XH, Jiang LX, Shi YJ, Gao MM, Yang S, Wang SG. Effects of step-feed on granulation processes and nitrogen removal performances of partial nitrifying granules. Bioresour. Technol. 2012;123:375-381.

23. Puig S, Vives MT, Corominas L, Balaguer MD, Colprim J. Wastewater nitrogen removal in SBRs, applying a step-feed strategy: from lab-scale to pilot-plant operation. Water Sci. Technol. 2004;50:89-96.

24. Yang Q, Peng YZ, Liu XH, Zeng W, Mino T, Satoh H. Nitrogen removal via nitrite from municipal wastewater at low temperatures using real-time control to optimize nitrifying communities. Environ Sci. Technol. 2007;41:8159-8164.

25. Guo JH, Peng YZ, Yang Q, Wang SY, Chen Y, Zhao CH. Theoretical analysis and enhanced nitrogen removal perform- 
ance of step-feed SBR. Water Sci. Technol. 2008;58:795-802. 26. Lemaire R, Yuan ZG, Bernet N, Marcos M, Yilmaz G, Keller J. A sequencing batch reactor system for high-level biological nitrogen and phosphorus removal from abattoir wastewater. Biodegradation 2009;20:339-350.

27. Ratusznei SM, Rodrigues JAD, de Camargo EFM, Ribeiro R, Zaiat M. Effect of feeding strategy on a stirred anaerobic sequencing fed-batch reactor containing immobilized biomass. Bioresour. Technol. 2003;90:199-205.

28. Wu X, Zhu J, Cheng J, Zhu N. Optimization of three operating parameters for a two-step fed sequencing batch reactor (SBR) system to remove nutrients from swine wastewater. Appl. Biochem. Biotechnol. 2015;175:2857-2871.

29. Obaja D, Mace S, Mata-Alvarez J. Biological nutrient removal by a sequencing batch reactor (SBR) using an internal organic carbon source in digested piggery wastewater. Bioresour. Technol. 2005;96:7-14.

30. Won SG, Ra CS. Biological nitrogen removal with a real-time control strategy using moving slope changes of $\mathrm{pH}(\mathrm{mV})-$ and ORP-time profiles. Water Res. 2011;45:171-178.

31. Arbabi M, Akbarzadeh A, Khodabakhshi A. Optimization of SBR system for enhanced biological phosphorus and nitrogen removal. Int. J. Eviron. Health Eng. 2012;1:49.

32. Hadipour A, Rajaee T, Hadipour V, Seidirad S. Multi-criteria decision-making model for wastewater reuse application: a case study from Iran. Desalin. Water Treat. 2016;57:13857-13864.

33. Zorpas AA, Saranti A. Multi-criteria analysis of sustainable environmental clean processes for the treatment of winery's wastewater. Int. J. Glob. Environ. Issues. 2016;15:151-168.

34. Kalbar PP, Karmakar S, Asolekar SR. Assessment of wastewater treatment technologies: life cycle approach. Water Environ. J. 2013;27:261-268.

35. Peng C, Du H, Liao TW. A research on the cutting database system based on machining features and TOPSIS. Robot. Comput. Integr. Manuf. 2017;43:96-104.

36. APHA (American Public Health Association). Standard methods for the examination of water and wastewater. Washington D.C: APHA; 2005.

37. Hwang CL, Yoon K. Methods for multiple attribute decision making. In: Multiple Attribute Decision Making. Springer, Berlin, Heidelberg; 1981. p. 58-191.

38. Oluah C, Akinlabi ET, Njoku H. Selection of phase change material for improved performance of Trombewall systems us- ing the entropy weight and TOPSIS methodology. Energy Build. 2020;217:1099667.

39. Işı AT, Adalı EA. The decision making approach based on the combination of entropy and ROV methods for the apple selection problem. Eur. J. Interdiscip. Stud. 2017;3:80-86.

40. Jha R, Singh VP. Evaluation of riverwater quality by entropy. KSCE J. Civil Eng. 2008;12:61-69.

41. Song W, Ming X, Wu Z. Failure modes and effects analysis using integrated weight-based fuzzy TOPSIS. Int. J. Comput. Integr. Manuf. 2013;26:1172-1186.

42. Ding L, Shao Z, Zhang H, Wu D. A comprehensive evaluation of urban sustainable development in China based on the TOPSIS-Entropy method. Sustainability 2016;8:746.

43. Liu S, Daigger GT, Liu B, Zhao W, Liu J. Enhanced performance of simultaneous carbon, nitrogen and phosphorus removal from municipal wastewater in an anaerobic-aerobic-anoxic sequencing batch reactor (AOA-SBR)system by alternating the cycle times. Bioresour. Technol. 2020;301:122750.

44. He Q, Song J, Zhang W, Gao S, Wang H, Yu J. Enhanced simultaneous nitrification, denitrification and phosphorus removal through mixed carbon source by aerobic granular sludge. $J$. Hazard. Mater. 2020;382:121043.

45. Xu Z, Dai X, Chai X. Effect of different carbon sources on denitrification performance, microbial community structure and denitrification genes. Sci. Total Environ. 2018;634:195-204.

46. Yoshida Y, Takahashi K, Saito T, Tanaka K. The effect of nitrite on aerobic phosphate uptake and denitrifying activity of phosphate-accumulating organisms. Water. Sci. Technol. 2006;53:21-27.

47. Zhou Y, Pijuan M, Yuan ZG. Free nitrous acid inhibition on anoxic phosphorus uptake and denitrification by poly-phosphate accumulating organisms. Biotechnol. Bioeng. 2007;98:903-912.

48. Milani AS, Shanian A, Madoliat R. The effect of normalization norms in multiple attribute decision making models: a case study in gear material selection. Struct. Multidiscip. Optim. 2005;29:312-318.

49. Chakraborty S, Yeh C. A simulation comparison of normalization procedures for TOPSIS. In: International Conference on Computers and Industrial Engineering; 6-9 July 2009; Troyes, France. p. 1815-1820.

50. Liu D, Qi XC, Fu Q, et al. Aresilience evaluation method for a combined regional agricultural water and soil resource system based on Weighted Mahalanobis distance and a Gray-TOPSIS model. J. Clean. Prod. 2019;229:667-679. 